\title{
Blast resistant design and limits of the response of a structure to an external explosion
}

\author{
D. Makovička ${ }^{1} \&$ D. Makovička $\mathrm{Jr}^{2}$ \\ ${ }^{1}$ Czech Technical University in Prague, Klokner Institute, Czech Republic \\ ${ }^{2}$ Static and Dynamic Consulting, Czech Republic
}

\begin{abstract}
A 3-D dynamic analysis of an entire structure is used to determine the effects of an explosion and the response of a structure. Damage to the structure is assessed accordingly, firstly by the angle of rotation of the middle axis/surface, and secondly by the limit internal forces of the selected structure. The extreme nature of blast resistance makes it necessary to accept that structural members have some degree of inelastic response in most cases. This enables the application of structure dissipation using the ductility factor. The limits are correlated with qualitative damage expectations. The methodology for dynamic response assessment and its application to the new RC building is discussed.

Keywords: explosion, dynamic analysis, structure response, failure assessment.
\end{abstract}

\section{Introduction}

When a blasting charge explodes in an open area, the action of the pressure of the shock wave on an obstruction depends on how the structure is situated with respect to the focus of the explosion, on the path from the explosion to the structure, on the characteristics of the loaded structure, and on the shock wave parameters on contact with the building. During an actual event, the specific course of action of the load depends on the whirl bypass of the surface of the structure, on the atmospheric pressure, on the temperature conditions and other factors which are usually neglected for a simplified analysis. The parameters of the explosive are also determined on the basis of mean values; the formulas that are used are empiric and operate with mean (probable) factor values. Thus the calculations of structures for shock wave effects are significantly influenced by these inaccuracies in the input quantities of the whole phenomenon. 
In our specific case, the effects of an explosion are applied to an administrative building where an ordinary vehicle can be used to bring a terrorist charge on a road close to the building, and the charge can be initiated near the building.

\section{Explosion load}

The explosion load is very often substituted as follows to achieve simplification $[1,2]$ :

a) Triangle-shaped development of the load in time with the maximum intensity corresponding to the sum of the pressures of the impacting and reflected wave and the duration of the action, usually corresponding only to the duration of the action of the overpressure phase of the shock wave;

b) The shock wave can be considered as having a flat front, meaning that the rise time to maximum intensity is neglected, and additionally that the load starts to act on the entire structure at one moment; the phase shift of the start of the action of the load at individual structure points is thus neglected;

c) It is usually assumed that the load acts on the building structure (walls, ceiling, windows, etc.) in a continuous and uniform manner (any local effect of the focused load is neglected);

d) The response of the structure is usually considered on the basis of the superimposition of two triangular loads, which correspond to the overpressure phase and subsequently the underpressure phase of the shock wave.

The authors used empirical formulas [2,3] applicable to an explosive charge in an open area to calculate the dynamic load; the formulas were derived from tests using small explosive charges; then the overpressure value $p_{+}$at the front of the aerial shock wave and its duration $\tau_{+}$are as follows:

$$
\begin{gathered}
p_{+}=\frac{1.07}{\bar{R}^{3}}-0,1 \quad[\mathrm{MPa}] \quad \text { for } \bar{R} \leq 1 \mathrm{~m} / \mathrm{kg}^{1 / 3} \\
p_{+}=\frac{0.0932}{\bar{R}}+\frac{0.383}{\bar{R}^{2}}+\frac{1.275}{\bar{R}^{3}} \quad[\mathrm{MPa}] \quad \text { for } 1<\bar{R} \leq 15 \mathrm{~m} / \mathrm{kg}^{1 / 3} \\
p_{-}=\frac{0,035}{\bar{R}} \quad[\mathrm{MPa}] \\
\tau_{+}=1.6 \cdot 10^{-3} \cdot \sqrt[6]{C_{\mathrm{w}}} \cdot \sqrt{R} \quad[\mathrm{~s}] \\
\tau_{-}=1.6 \cdot 10^{-2} \cdot \sqrt[3]{C_{\mathrm{w}}} \quad[\mathrm{s}]
\end{gathered}
$$

For reduced distance

$$
\bar{R}=\frac{R}{\sqrt[3]{C_{\mathrm{w}}}}\left[\mathrm{m} / \mathrm{kg}^{1 / 3}\right]
$$


where $\bar{R}$ is the reduced distance from the epicentre of the explosion, $R$ is the distance from the explosion epicentre [m], and $C_{w}$ is the equivalent mass of the explosive charge [kg TNT].

The wave motion from the explosion focus propagates in spherical wave fronts. In the event of a surface explosion (at the contact point with the ground), the explosion energy value is about double, given that when there is complete reflection from the ground surface the shock wave propagates in semi-spherical wave fronts. For a surface explosion, this effect can as a rule be taken into account by substituting twice the magnitude of the actually used mass of charge $C$ for the equivalent mass of charge $C_{\mathrm{w}}$ in formula (5). For an above-ground explosion at a height of more than $20 \mathrm{~m}$ above ground, the mass of the charge $C$ is substituted directly (without any increase in its value) for the equivalent mass of the charge. For a charge placed between the ground level (zero height) and 20 $\mathrm{m}$ above the ground, linear interpolation can be used to determine the equivalent mass of the charge; in this case, the equivalent mass of the charge substituted to the formulas above will range between

$$
C_{w}=(1 \text { to } 2) C
$$

When there is a normal (perpendicular) impact of the explosion wave against a solid barrier, a reflected wave is formed with the reflection overpressure $p_{\text {ref }}$, which loads the building structure from the front side. The overpressure value in the reflected wave corresponds to approximately twice the overpressure for low overpressure values $p_{+}$approximately up to $5 \mathrm{MPa}$ (up to eight times the value for high overpressures of several tens of $\mathrm{MPa}$ ) in the impact wave for the given distance $R$. The duration of the action of the overpressure $t_{\mathrm{D}}$ is about the same as the duration of shock wave $\tau_{+}$

$$
\begin{gathered}
p_{\text {ref }+} \approx 2 p_{+} \\
t_{\mathrm{D}} \approx \tau
\end{gathered}
$$

\section{Response calculation taking into account the ductility of the structure}

The structure response is generally calculated and assessed in accordance with design standards for the given type of structure material. In our case, Eurocodes are used. The dynamic response to the effects of the load due to an explosion must be superimposed on the effects due to static loads. These are usual procedures, but it should be noted that when the structure is loaded due to an explosion, inelastic deformations occur at a number of sections, causing damage to the structure by crack formation. In this case, the stability of the structure with the cracks should be assessed in order to prevent any collapse of the structure due to the formation of plastic joints and cracks.

When a structure is loaded by an explosion, the formation of cracks not leading to a collapse is as a rule permitted. Thus ductility factor $q$ may be used to 
reduce the magnitude of the explosion load. This is a highly efficient way of taking inelastic manifestations of the dynamic load into account.

$$
q=x_{\mathrm{m}} / x_{e l}
$$

where $x_{m}$ is the maximum elastic plastic displacement of the structure, and $x_{e l}$ is the elastic part of the displacement.

The applicable ductility factor is usually $q<3$ for reinforced concrete structures. On the basis of a more detailed analysis of the structure, higher ductility factor values may be used, for example, on the basis of seismic standard EN 1998-1 [4].

The strength characteristics of the structure material may also be increased in the calculation of the structure response. An estimate of this increase (material strengthening factor $k_{1}$ ) is shown in Table 1, in dependence on the duration of the explosion load effect $t_{\mathrm{D}}$.

Table 1: $\quad$ Estimate of factor $k_{1}$ in dependence on load duration $t_{\mathrm{D}}$.

\begin{tabular}{|c|c|c|c|c|}
\hline$t_{\mathrm{D}}[\mathrm{s}]$ & $\geq 1.0$ & $10^{-1}$ & $10^{-2}$ & $10^{-3}$ \\
\hline$k_{1}$ & 1.0 & 1.05 & 1.10 & 1.20 \\
\hline
\end{tabular}

\section{Evaluation of the structure response}

The magnitudes of the internal forces in the structure are considered as a part of the evaluation of the limit bearing capacity conditions, based on load combinations when they are reduced using ductility factor $q[4-6]$. The resulting internal forces are then evaluated on the basis of design standards for the appropriate structure material type, or as a variant, also according to its increased strength using factor $k_{1}$. However, this procedure entails two important uncertainties in the case of bent structures, i.e. a suitable choice of the ductility factor, on the one hand, and the material strengthening factor, on the other. During very rapid reshaping of the structure, which is typical for explosion loads, both factors may achieve numeric values of the order of tens, and not only of units, as mentioned above. Thus they may lead to considerable overdesigning of the structure.

Evaluations of structures loaded by an explosion based on dynamic displacement and swinging round the central line of plate, wall or beam systems during the action of a dynamic load of this type have been of very topical interest in recent times, as regards the process of evaluating the effects of an explosion on a structure.

In earlier publications, the authors applied this procedure to various types of materials and structure systems, and on the basis of an experimental comparison they determined the failure angle $\psi_{\max }$, i.e. the angle where damage is caused to the structure by breaking. 
The dynamic rotation round the central line of an appropriate structure element is therefore the criterion used to evaluate the response occurring at the following angle

$$
\psi=\operatorname{arctg}\left(x_{\mathrm{m}} /\left(0.5 h_{\mathrm{span}}\right)\right)
$$

where $x_{\mathrm{m}}$ is the maximum achieved dynamic displacement caused by the explosion load and $h_{\text {span }}$ is the span of the plate ceiling structure or the height of the wall structure within one storey, or the span of any beam, the height of a column, etc.

The approximate failure angle value on reaching the rupture limit value is shown in Table 2. More conservative limit values of angle $\psi$ were derived according to $[7,8]$, which correspond to the chosen structure rupture risk. These values have been adapted and are shown in Table 3.

Table 2: $\quad$ Limit failure angle $\psi_{\max }\left[{ }^{\circ}\right]$ upon breaking of the material $[2,3]$.

\begin{tabular}{|c|l|c|}
\hline Type & Structure material & $\psi_{\max }\left[^{\circ}\right]$ \\
\hline 1 & Concrete C16/20 to C40/50 & 6.5 \\
\hline 2 & Masonry, full bricks 10, mortar 4 or mortar 10 & 5.0 \\
\hline 3 & Masonry, cement bricks, mortar 4 & 4.5 \\
\hline 4 & Masonry, cellular concrete or perforated precise blocks, mortar 4 & 4.0 \\
\hline 5 & Steel S235 & 10.5 \\
\hline 6 & Wood, hard and soft & 12 \\
\hline 7 & Window glass, thickness $3 \mathrm{~mm}$ & 6 \\
\hline
\end{tabular}

Table 3: $\quad$ Angle $\psi\left[{ }^{\circ}\right]$ of the expected damage to bent structural elements $[2,7]$.

\begin{tabular}{|l|c|c|c|}
\hline \multirow{2}{*}{ Structure } & \multicolumn{2}{|c|}{ Expected damage to elements } \\
\cline { 2 - 4 } & Mean & High & Hazardous \\
\hline $\begin{array}{l}\text { Reinforced concrete structures, plates and } \\
\text { beams with one-sided reinforcement }\end{array}$ & 2 & 5 & 10 \\
\hline $\begin{array}{l}\text { Reinforced concrete structures, plates and } \\
\text { beams with two-sided reinforcement and }\end{array}$ & 4 & 6 & 10 \\
\hline $\begin{array}{l}\text { Prestressed concrete, beams and plates } \\
\text { Masonry, common, non-reinforced }\end{array}$ & 1 & 1.5 & 2 \\
\hline Masonry, reinforced & 1.5 & 4 & 8 \\
\hline Steel bars & 2 & 8 & 20 \\
\hline
\end{tabular}

The mean occurrence of damage corresponds to the damage to reinforced concrete or masonry elements, e.g. spalling, or the occurrence of tiny cracks in 
the structure elements, which pose no threat to their stability and can be repaired, e.g. by grouting.

However, hazardous occurrence of damage approaches emergency level damage, and its failure angle is found at the lower limit, below the maximum failure angle value $\psi_{\max }$, see Table 2 .

The reinforced concrete wall structure of the building (Fig. 1) was designed to sustain the effects of a terrorist charge explosion characterized by the load $p_{\text {ref }}=$ $320 \mathrm{kPa}$ and triangular pulse of the load $2200 \mathrm{kPa} \cdot \mathrm{ms}$, i.e. with overpressure in the shock wave of $p_{+}=160 \mathrm{kPa}$ and duration $t_{+}=14 \mathrm{~ms}$.
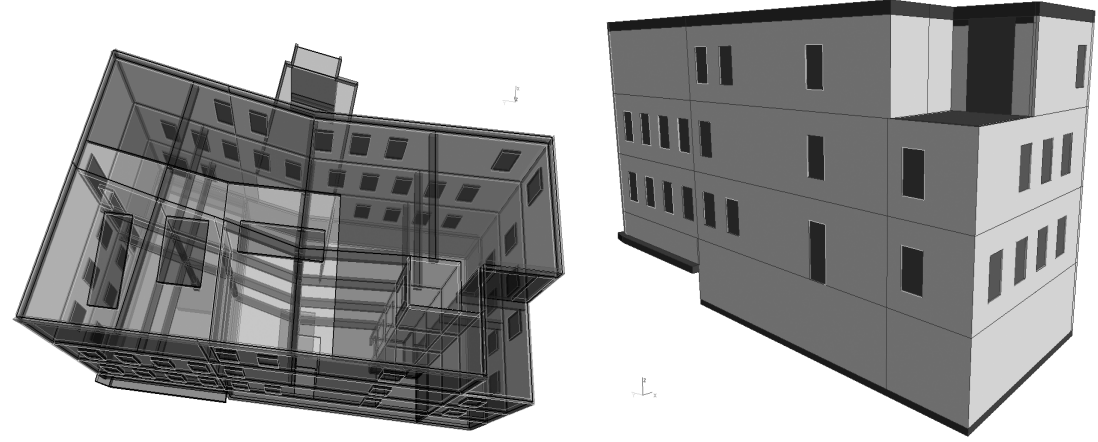

Figure 1: Calculation model of the the whole structure, north-west and top views.

Table 4: Characteristics of the explosion load areas of the front wall (see Fig. 2).

\begin{tabular}{|c|c|c|c|c|}
\hline Characteristics & Zone 1 & Zone 2 & Zone 3 & Zone 4 \\
\hline $\begin{array}{c}\text { Radius of the circle or } \\
\text { annulus round the normal } \\
\text { line of the shock wave impact } \\
{[\mathrm{m}]}\end{array}$ & 5 & 5 to 9 & 9 to 13 & more than 13 \\
\hline Impacting wave & $\begin{array}{c}\mathbf{p}_{+}=160 \mathrm{kPa} \\
\tau_{+}=14 \mathrm{~ms}\end{array}$ & $\begin{array}{c}\mathbf{p}_{+}=140 \mathrm{kPa} \\
\tau_{+}=14 \mathrm{~ms}\end{array}$ & $\begin{array}{c}p_{+}=111 \mathrm{kPa} \\
\tau_{+}=15 \mathrm{~ms}\end{array}$ & $\begin{array}{r}p_{+}=84 \mathrm{kPa} \\
\tau_{+}=16 \mathrm{~ms}\end{array}$ \\
\hline Impact angle $\left[{ }^{\circ}\right]$ & 90 to 70 & 70 to 57 & 57 to 47 & 47 and less \\
\hline $\begin{array}{l}\text { Start of action of the load } \\
\text { from the time of the wave } \\
\text { impact on the wall } t^{*}[\mathrm{~ms}]\end{array}$ & $\mathbf{0}$ & +2 & +8 & +16 \\
\hline $\begin{array}{l}\text { Dynamic load due to } \\
\text { reflection overpressure [kPa] }\end{array}$ & 320 & 280 & 222 & 168 \\
\hline
\end{tabular}




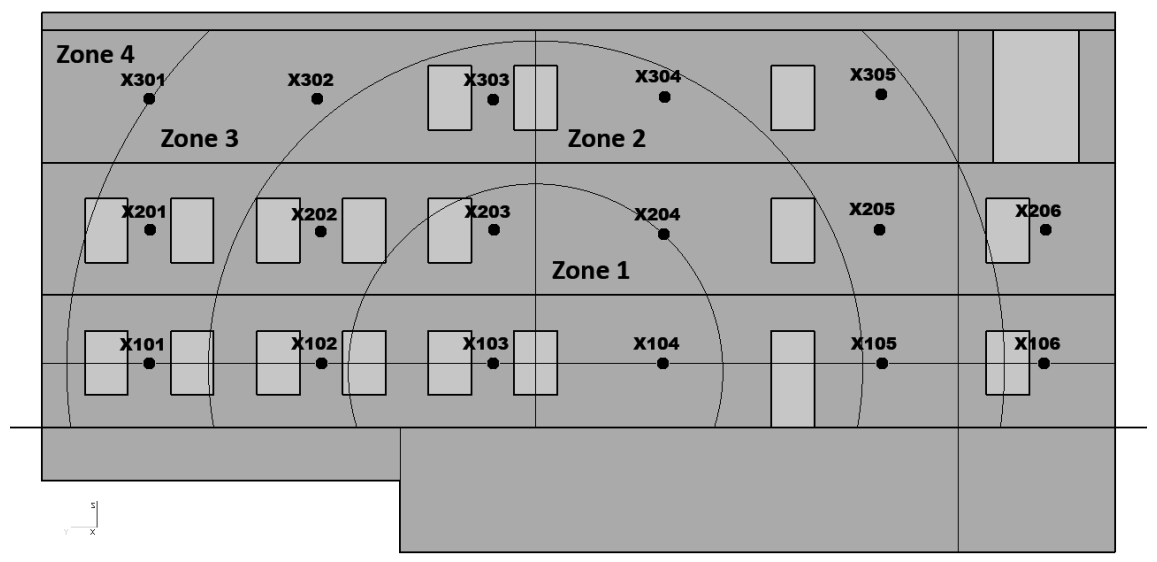

Figure 2: Calculation model, selected nodes for time history graphs.

On substitution to formulas (1) to (5), charge $C=125 \mathrm{~kg}$ at distance $R=13.8$ $\mathrm{m}$ from the building corresponds to this shock wave. For an explosion height above ground equal to $1.8 \mathrm{~m}$ (window level of the building), the equivalent charge mass is $C_{\mathrm{w}}=171.3 \mathrm{~kg}$ TNT.

To simplify the considerations, the explosion is deemed to load the front wall of the structure stepwise in parts, continuous, in four zones corresponding to the duration of action of the impacting aerial shock wave, with the reflection factor equal to approximately 2 , according to equation (7).

The forced vibration of the building in response to the effects of the explosion was resolved by decomposing it to the natural shapes of the vibration of the building. Relative attenuation of the structure equal to $5 \%$ was used to calculate the response.

The dissipative characteristics of the structure were taken into account by applying the ductility factor, set as equal to 2.5 for plate structures and horizontal beams, and equal to 1.5 for columns. To provide an example of the nature of the rotation of median fibres of the face wall, Fig. 3 and Fig. 4 show isolines of the rotations in the front wall of the building (from the side of the explosion) around the $z$ and $y$ axes in the plus and minus directions.

The maximum rotation value of the front wall round the vertical $z$ axis was from $+0.40^{\circ}$ to $-0.43^{\circ}$, and round the horizontal longitudinal $y$ axis the value was from $+0.29^{\circ}$ to $-0.36^{\circ}$.

A comparison of these whole rotations $0.83^{\circ}$ about $z$ and $0.65^{\circ}$ about $y$ with the values in Table 3 slows clearly that the structure of the front wall is sufficiently safe against major damage. Its rotation values are lower than the limit failure angle $\psi_{\max }=2^{\circ}$, which corresponds to the mean damage to the structure. 
The formation of only tiny, predominantly capillary cracks can thus be expected in this external wall at the points where the partition walls connect to the external wall, in the staircase part.

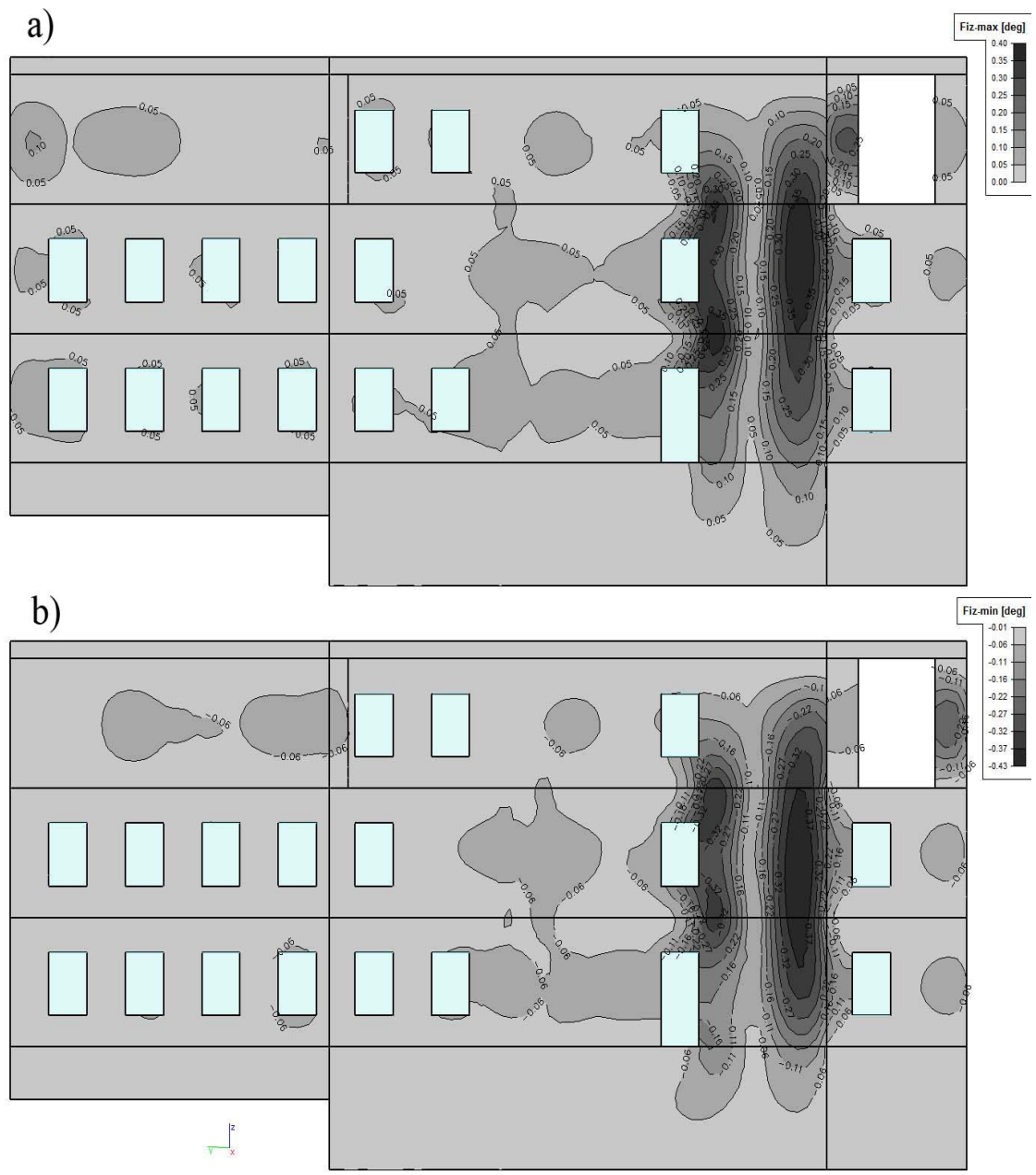

Figure 3: North wall, rotation round the $z$ axis; a) max rotation, b) min rotation. 
a)

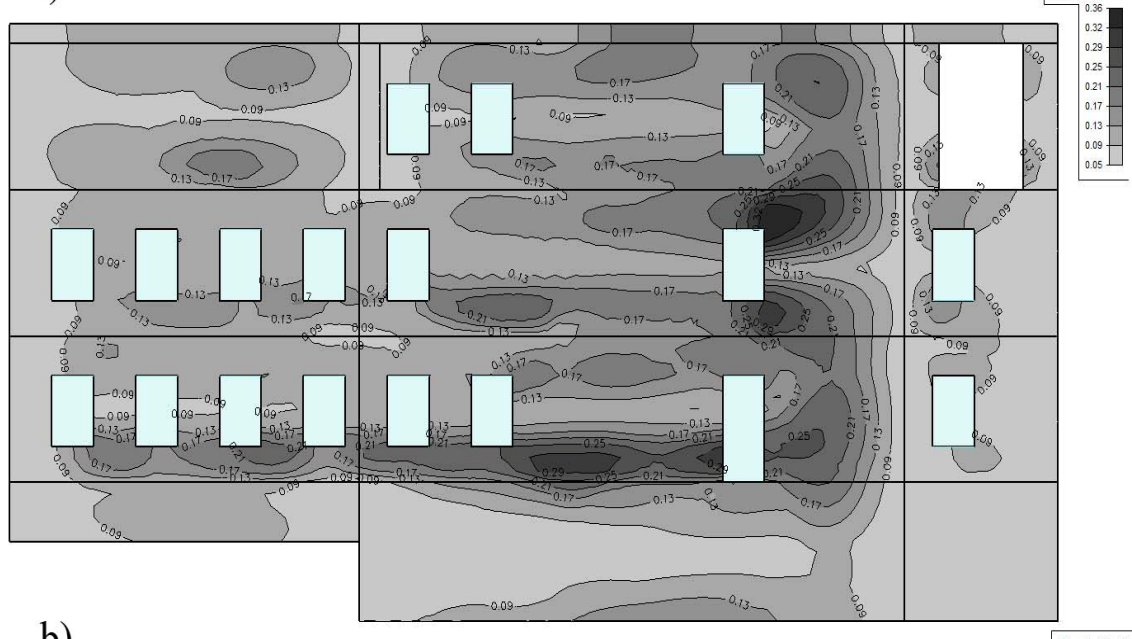

b)

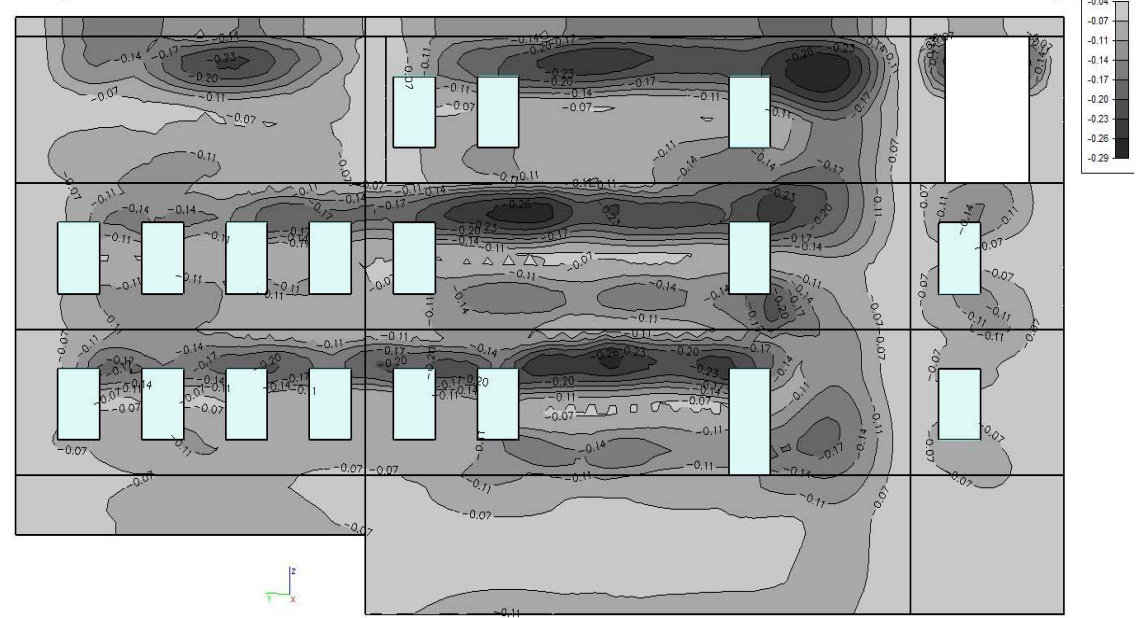

Figure 4: North wall, rotation round the $y$ axis; a) max rotation, b) min rotation.

Fig. 5 shows the time history of the displacements in selected points (see Fig. 2) of the ground floor on the frontal north wall oriented toward the epicentre of the explosion.

\section{Conclusion}

A specific building was used as an example to illustrate the problem of an explosion and the threat to the safety of the structure due to the explosion of a 


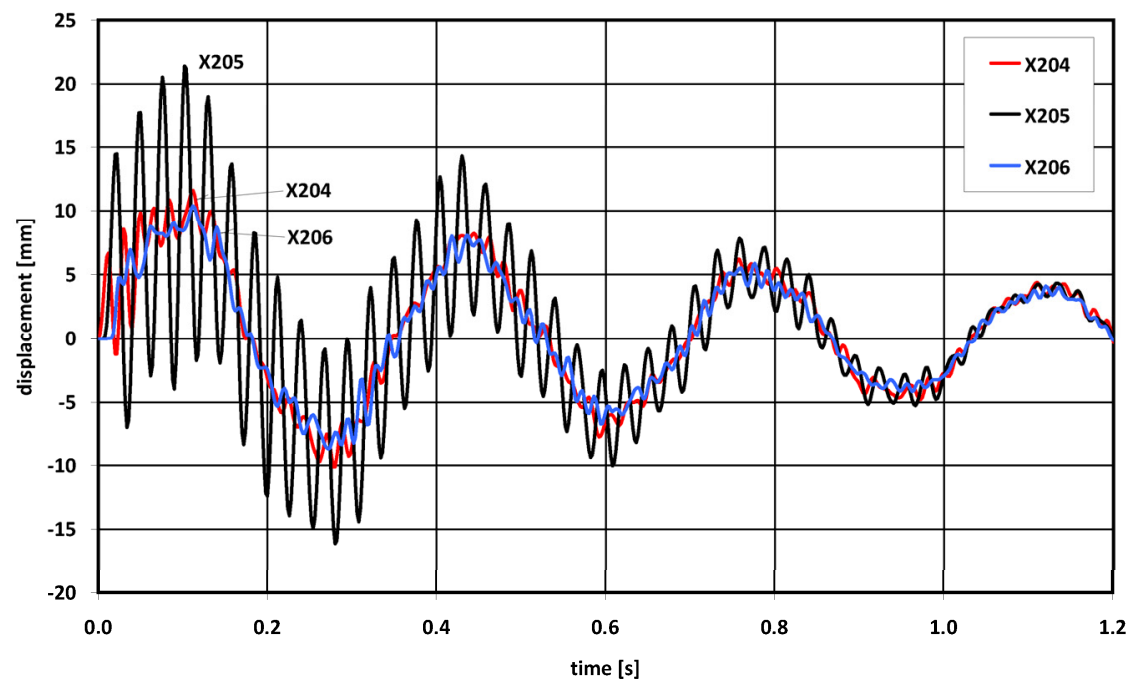

Figure 5: Vibration $u_{\mathrm{x}}$ in selected points (see Fig. 2) of the north wall of the ground floor in transversal direction $x$.

rather large terrorist charge installed in a car and initiated on a road adjacent to the building.

The explosion load due to an outside emergency or a terrorist explosion is usually burdened with a number of uncertainties, related to determining the amount of explosive medium, its location in relation to the loaded structure, and the conditions in the surroundings. A methodology derived by the authors based on the experimental results of small charge explosions has been used for an engineering estimate of the probable explosion load. This methodology enables us to determine with sufficient accuracy the time course of the impacting shock wave and its interaction with the structure itself.

The structure response was assessed on the basis of the results of a $3 \mathrm{D}$ dynamic calculation using the magnitudes of the internal forces and deflections and rotation of the central line of beam or plate sections of the structure. Evaluating a structure on the basis of the rotation of its sections is a methodology under development at present, and is in accordance with recent research trends. The authors have used limit rotation values (failure angle) determined experimentally on the basis of the explosion load of masonry, reinforced concrete and window glass plates, comparing their own results [2, 3, 9] with results published by other authors [1, 6-8].

A reinforced concrete administrative building has been used as an example for determining and documenting the load due to a terrorist explosion. The results for the response of the building to this load are presented in parts, together with the principles for evaluating the structure according to the internal forces in its structure and according to the failure angle corresponding to the given explosion load. 


\section{Acknowledgement}

This research was supported as a part of the research projects in GAČR P105/11/1580 Transient response of structure under short-term dynamic or impact load due to seismic effects and explosions, for which the authors would like to thank the Agency.

\section{References}

[1] Henrych, J., The Dynamics of Explosion and Its Use, Academia: Prague, 1979.

[2] Makovička, D. and Janovský, B., Handbook of Explosion Protection for Buildings (in Czech), CTU Publishing House: Prague, 2008.

[3] Makovička, D., Shock wave load of window glass plate structure and hypothesis of its failure, Structures Under Shock and Impact '98, ed. C.A. Brebbia, WIT Press: Southampton, pp. 43-52, 1998.

[4] ČSN EN 1998-1 Eurocode 8, Design of structures for earthquake resistance - Part 1: General rules, seismic actions and rules for buildings, ČNI: Praha, 2006.

[5] USNRC regulatory Guide 1.91, Evaluation of explosions postulated to occur on transportation routes near nuclear power plant sites, U. S. Nuclear Regulatory Commission, 1978.

[6] TM 5-1300: Structures to resist the effect of accidental explosions, U. S. Army Corps of Engineers: Washington, D.C., (Navy NAVFAC P-397 or Air Force AFR 88-22), 1990.

[7] McCann, D.M. and Smith, S., J., Blast resistant design of reinforced concrete structures, STRUCTURE magazine, pp. 22-26, April 2007.

[8] Design of Blast Resistant Building in Petrochemical Facilities, American Society of Civil Engineers: Reston, VA, 1997.

[9] Makovička, D., Makovička, D.: Simplified evaluation of a building impacted by a terrorist explosion, In: Jones, N., Brebbia, C.A.: Structures Under Shock and Impact XI, WIT Press, Southampton, 2010, pp. 93-104.

[10] Makovička, D., Makovička, D., Explosion of a charge in the interior of a structure and its impact on the structure (in Czech), Spektrum, 10/2, pp. 2023, 2010. 